\title{
Using the Semantic Differential Technique to Assess Stereotypes toward Individuals with Disabilities: The Relevance of Warmth and Competence*
}

\author{
Utilización de la técnica del diferencial semántico para evaluar \\ estereotipos hacia personas con discapacidades: La relevancia de la \\ calidez y competencia
}

Received: 21 November 2015 | Accepted: 26 April 2018

\author{
Cristina Jenaro \\ Universidad de Salamanca, España \\ ORCID: http://orcid.org/0000-0003-2060-1658 \\ Noelia Flores \\ Universidad de Salamanca, España \\ ORCID: http://orcid.org/0000-0001-9822-7235 \\ JEsús López-Lucas \\ Universidad de Salamanca, España \\ ORCID: http://orcid.org/0000-0002-9114-2922
}

a Correspondence author. Email: crisje@usal.es

How to cite: Jenaro, C., Flores, N., \& López-Lucas, J. (2018). Using the semantic differential technique to assess stereotypes toward individuals with disabilities: The relevance of warmth and competence. Universitas Psychologica, 17(4), 1-12. https:// doi.org/10.11144/Javeriana.upsy17-4.usdt

\begin{abstract}
This study analyzes social perceptions towards groups with different types of disability, as well as the relationship between the judgments towards these groups, oneself and other significant individuals. The assessment was carried out using a Semantic Differential scale completed by181 participants. Results supported the Stereotype Content Model, as the different groups with disabilities were perceived in a more uniform way than those who did not share this label, and people with intellectual disability elicited paternalistic feelings. The results also support a twofactor model to explore the content of the stereotypes. Understanding the factors that contribute to the formation of social judgments is key to the implementation of actions that modify stereotypes and prejudices and promote equity.
\end{abstract}

Keywords

Stereotypes; Disabilities; Assessment; Semantic Differential; Attitudes.

\section{RESUMEN}

Este estudio analiza las percepciones sociales hacia grupos con diferentes tipos de discapacidad, así como la relación entre los juicios hacia dichos grupos, uno mismo y otros significativos. La evaluación fue realizada mediante un Diferencial Semántico aplicado a 181 estudiantes universitarios. Los resultados apoyaron el Modelo de Contenido de los Estereotipos, pues los grupos con discapacidad fueron percibidos de una manera más uniforme que quienes no comparten esta etiqueta y las personas con discapacidad intelectual suscitaron sentimientos paternalistas. Los resultados avalaron además la adecuación de un modelo bifactorial para explorar el contenido de los estereotipos. Comprender los factores que contribuyen a la formación de los juicios sociales es clave para 
la puesta en marcha de acciones que modifiquen estereotipos y prejuicios y promuevan la equidad.

Palabras clave

Estereotipos; Discapacidades; Evaluación; Diferencial Semántico; Actitudes.

Attitudes are theoretical constructions which consist of cognitive, affective and conativebehavioral components. Such constructs are under the domain of specific stimuli or reference objects (for example, individuals, social groups). These referents, by virtue of their perceived social value, are capable of eliciting an attitudinal response. In this sense, attitudes can be conceived as mediators between a stimulus from the environment and behavioral responses (Arias, Arias, Verdugo, Rubia, \& Jenaro, 2016). In light of this definition, it is clear that attitudes toward individuals with disabilities are related to the opportunities for their successful integration into the community (Goreczny, Bender, Caruso, $\&$ Feinstein, 2011).

The process of attitude formation toward other people has been studied under the framework of interpersonal perception. This has been defined as the process of gaining orientation in the characteristic features of other people (Bąk, 2001). It includes three correlated components: (1) the attribution of permanent and temporary characteristics of people; (2) expectations toward their behavior; and (3) emotions in relation to them. In turn, the process of interpersonal perception results in the subjective perception of the social environment (i.e., the others) or social judgments. In this regard, according to the Stereotype Content Model (SCM) (Fiske, Cuddy, Glick, \& Xu, 2002), there are two fundamental dimensions of social judgments about individuals and social groups, namely, warmth (e.g., friendliness, trustworthiness, kindness), and competence (e.g., intelligence, efficacy, skills) (Abele, Cuddy, Judd, \& Yzerbyt, 2008; Binggeli, Krings, \& Sczesny, 2014; Kotzur, Forsbach, \& Wagner, 2017; Ponsi, Panasiti, Scandola, \& Aglioti, 2016). Warmth has been defined by some authors as commonality, while competence has also been referred to as competence or agency (Kervyn, Fiske, \& Yzerbyt, 2013). Perceived levels of competence and warmth indicate to what extent a group is, respectively, respected and liked, (Collange, Fiske, \& Sanitioso, 2009) and, in consequence, the behaviors that will be enacted toward them (Araten-Bergman \& Werner, 2017; Nelissen, Hülsheger, van Ruitenbeek, \& Zijlstra, 2016). Also, the primacy of the warmth dimension over competence (Fiske Cuddy, \& Glick 2007; Richetin, Durante, Mari, Perugini, $\&$ Volpato, 2012) is typical for judging distant persons (Wojciszke \& Abele, 2008), but it is reversed when judging the self or interdependent others (Lindqvist, Björklund, \& Bäckström, 2017; Richetin et al. 2012).

Context is key when determining which of the two fundamental dimensions of warmth and competence will have more significant influence on social judgment (Smith \& Semin 2007), and so, high-status groups tend to see themselves as more competent than warm, while the opposite is true for low-status groups (de Paula Couto \& Koller, 2012; Nier, Bajaj, McLean, \& Schwartz, 2013; Oldmeadow \& Fiske, 2012; Richetin et al. 2012).

A particular form of social categorization is the stereotype, which constitutes an overgeneralization and simplification of reality and is cognitive, as well as emotional and evaluative (Bąk, 2001). The intersection of the previously mentioned two bipolar dimensions may lead to stereotypes consisting of characterizing a social group as cold and competent, cold and incompetent, warm and competent, or warm and incompetent (Álvarez Pascual \& Jenaro, 2018). Literature reveals (Binggeli et al., 2014) that most groups are targets of mixed stereotypes that help to justify the status quo (Durante, Tablante, \& Fiske, 2017) and to elicit ambivalent feelings (Dijker, van Alphen, Bos, van den Borne, \& Curfs, 2011).

In addition, four emotions are associated with the four different stereotypes resulting from the combinations of warmth and competence. These are contempt (low warmth low competence), admiration (high warmth high competence), pity (high warmth low competence), and envy (low 
warmth high competence) (de Paula Couto \& Koller, 2012). According to Fiske et al. (2002), paternalized groups elicit pity and sympathy (Collange et al., 2009; Cottrell \& Neuberg 2005; Fiske et al., 2002). Thus, some disadvantaged groups, such as people with disabilities, are perceived as warm, but at the same time as incompetent (Carlsson \& Björklund, 2010; Cuddy, Fiske, \& Glick, 2008; Cuddy et al., 2009; Durante, Volpato, \& Fiske, 2010; Fresson, Dardenne, Geurten, \& Meulemans, 2017). In other words, nowadays, people with disabilities, with the exception, perhaps, of the most stigmatized groups such as those with mental illness (Araten-Bergman \& Werner, 2017; Follmer \& Jones, 2017; Jahoda \& Markova 2004; Oexle, Müller, et al., 2017; Oexle, Rüsch, et al., 2017), are generally accepted and their fundamental rights recognized, at least in Western society. However, the achievement of full citizenship requires going beyond paternalistic stereotypes and subsequent emotions such as pity. Pity and sympathy are emotions that characterize stereotypes resulting from the high warmth and low competence and so, they can bring overprotection behaviors and may result in a reduction of rights to ensure the safety of target groups.

Among the different techniques to measure attitudes, semantic differential approaches have some advantages, such as being comprehensive and simple to administer (Chin, Johnson, \& Schwarts, 2008). They also allow using the same elements to rate different attitude objects or referents, which in turn can be used to compare those responses. The semantic differential developed by Osgood, Suci, and Tannenbaum (1957) is a technique to measure the meaning of attitudes and beliefs about a concept, phenomenon, or object through a set of opposite adjectives that are used to evoke a subject's feeling about, or evaluation of, the concept. According to Osgood et al. (1957) adjectives generally tend to reflect three dimensions: (a) evaluation, reflecting subjects' judgment about the concept; (b) potency, reflecting strength of the concept; and (c) activity reflecting the dynamic nature of the concept (Mariani \& Allen, 2014). In the present article, we propose that it is possible to draw a parallel between the dimensions of warmth and evaluation, and between the dimensions of competence and potency; these dimensions are also the most relevant for the development of social judgments. The activity dimension offers additional information about modifiability of certain attitudinal elements.

Semantic differential technique has been used to identify the perceptions of people with different disability conditions (Ahlborn, Panek, \& Jungers, 2008; Bąk, 2001; Fellinghauer, Roth, Bugari, \& Reinhardt, 2011; Lifshitz, 2002; Miyahara \& Register, 2000; Panek \& Jungers, 2008; Panek \& Smith, 2005). Research also reveals that typical characteristics of stereotypes (rigidity, overgeneralization, etc. ) appear when judging people with mental illness (Bąk, 2001), and that different "labels" toward a condition elicit different evaluation, potency, and activity scores (Panek \& Smith, 2005), with causality attributions of the disability being a relevant factor in explaining different attitudes (Panek \& Jungers, 2008).

Recently, it has been demonstrated that the Semantic Differential (SD) dimensions of evaluation and potency relate to the Stereotype Content Model dimensions (SCM) of warmth and competence (Kervyn et al., 2013). Both dimensions have an evaluative aspect, competence is better than incompetence, and being warm is better than being cold (Kervyn et al., 2013; Stephan \& Stephan 2000).

Although, as we mentioned earlier, several studies on attitudes toward people with disabilities using the semantic differential technique have been developed, many of these studies require a more solid theoretical foundation, terminological updates, and methodological improvements. Some of these improvements relate to further specification of the procedure used for the development of the measures, the reasons for selecting specific samples or for performing some analyzes. Additionally, no replications on the relations between the Semantic Differential (SD) dimensions of evaluation and potency and the 
Stereotype Content Model dimensions (SCM) of warmth and competence have been made in studies on individuals with disabilities.

In the disabilities field, there is also a lack of studies looking at the difference regarding the perceived distance between "them" and oneself (i.e., self, ideal self). Also, identifying differences in the stereotypes and associated emotions that several types of disabilities elicit deserves research efforts.

In this study, similar to what was done by Kervyn et al. (2013), we have combined two models of social perception; the semantic differential model proposed by Osgood and the Stereotype Content Model with the dimensions of warmth and competence. In our case, we are focusing the analysis on the identification of possible differences in the characterization of social groups with different disability labels.

More specifically, by means of two consecutive studies, we aim to: (1) determine the adequacy of the Osgood et al. (1957) and Fiske et al. (2002) models to assess perceptions towards individuals with disabilities and (2) analyze the differences and similarities in interpersonal perception, based on the characteristics of both the respondents and the attitudinal referents.

We predict that according to the Osgood framework and the SCM: (1) oneself will be characterized with positive (i.e., emergent) adjectives, as well as both warm and competent, whereas the different groups with disabilities will be characterized with less desirable characteristics; (2) the self will be characterized more competent than warm; (3) people with different disability levels will be subject of mixed feelings; (4) the primacy of warmth over competence will appear on judgments of distant people, whereas for oneself and close people, the opposite pattern will appear; (5) people with intellectual disabilities will be characterized as lower-status group than oneself, and consequently, they will be perceived as warmer rather than competent, and in turn, they will elicit paternalistic feelings.

\section{Method}

\section{Participants}

For the initial development of the measure, the participants consisted of a voluntary and convenience sample of 170 respondents made up of university students and disability organizations professionals, of whom $15.3 \%$ were male $(\mathrm{N}=$ 26) and $84.7 \%(\mathrm{~N}=144)$ female. Of the total, $40.6 \%(\mathrm{~N}=69)$ had no previous contact with people with intellectual disabilities, while $59.4 \%$ $(\mathrm{N}=101)$ did have. Contact was sporadic in 99 cases $(58.2 \%)$, habitual in $67(39.4 \%)$ and frequent in only four cases (2.4\%). In 14 cases the contact was for family reasons $(8.2 \%)$ and in 68 cases $(40 \%)$ the contact is due to work reasons. Ages ranged from 18 to 64 years (average $=26.9$; $\mathrm{SD}=10.8)$. The average age of practitioners was 45.8 years $(\mathrm{SD}=14.9$; range: $33-64)$, and the mean age of students was 19.7 (SD = 3.6; range: 18-46). Chi-square tests revealed that gender was similarly distributed among participants with different levels of experience with individuals with disabilities, as well as with different backgrounds and level of contact.

The second part of the study involved 181 college students, 29 (16\%) males and 152 (84\%) females, aged between 18 and 37 years (M $=21.5 ; \mathrm{SD}=3.6)$. Concerning contact with people with disabilities, $44.8 \%$ stated that they did not have frequent or regular contact with this population, while $55.2 \%$ indicated having it. All participated voluntarily after anonymity and confidentiality of information collected was guaranteed.

\section{Measures}

For the development of the SD, the selection of bipolar adjectives was made from the adjective listings proposed by Osgood (1952). We also added adjectives from the Scale for the Assessment of Attitudes Toward Persons with Disabilities (Polo Sánchez, Fernández Jiménez, \& Díaz Batanero, 2011; Verdugo, Arias, \& Jenaro, 1994). From a list of 16 bipolar adjectives (e.g. 
"good-bad"), five raters were asked to assign them to one of the three dimensions proposed by Osgood: (1) Evaluation: positive or negative; (2) Power: capacity; (3) Activity: dynamism and change. Analyses showed an average pairwise percentage of agreement of $88.125 \%$ (range: $81.25 \%$ to $93.75 \%$ ); Fleiss' kappa $=0.797$. The Average Pairwise Cohen's Kappa was = 0.795, and Krippendorff's Alpha was $=0.799$. According to Landis and Koch (1977), Cohen's and Fleiss' Kappa values higher than 0.80 denote high agreement, and according to Krippendorff (2004), Krippendorff's $\alpha$ values between 0.67 and 0.80 are acceptable. Thus, the bipolar adjectives are reliable to measure the three dimensions proposed by Osgood.

Additionally, an exploratory factor analysis was performed with the 16 bipolar adjectives, and the analysis resulted in three factors explaining $57.95 \%$ of variance. Factor 1 , with an eigenvalue of 5.73 , accounts for $35.796 \%$ of the variance and is composed of eight adjectives that assess the evaluation domain. Factor 2, with an eigenvalue of 2.276 , explains $14.23 \%$ of the variance and is composed of four potency adjectives. The third factor, with an eigenvalue 1.27, explains $7.93 \%$ of the variance and is composed of four adjectives related to activity (see Table 1 ). The predominance of adjectives centered on the evaluation component is warranted given that the scale aims at assessing attitudes, so the evaluation component is critical.

\section{Table 1}

Rotated component matrix

\begin{tabular}{lrrr}
\hline \multicolumn{1}{c}{ Bipolar adjectives } & 1 (Evaluation) & 2 (Potency) & 3 (Activity) \\
\hline Idle-Worker & & 0.580 & \\
Hostile-Friendly & 0.738 & & \\
Unable-Able & & 0.858 & \\
Incompetent-Competent & & 0.794 & \\
Intolerant-Tolerant & 0.572 & & 0.537 \\
Irresponsible-Responsible & & & \\
Poor coworker-Good coworker & & 0.683 & \\
Crabby-Kind & 0.820 & & \\
Bad-Good & 0.776 & & \\
Negative-Positive & 0.680 & & 0.842 \\
Child-Adult & & & 0.452 \\
Passive-Active & & & \\
Dangerous-Harmless & & & \\
Resented-Placid & 0.674 & & \\
Resigned-Hopeful & 0.634 & & \\
Sad-Happy & 0.782 & & \\
\hline
\end{tabular}

Note: Extraction method: Principal

Component Analysis; Rotation method.

Varimax with Kaiser Normalization
The analysis of the internal consistency of the three dimensions revealed a Cronbach's alpha $=0.625$ for Activity, a Cronbach's Alpha $=$ 0.873 for Evaluation, and a Cronbach's alpha $=$ 0.765 for Potency. The overall measure obtained a Cronbach's alpha $=0.863$. The analysis of correlations between Evaluation and Activity $\left(r_{x y}\right.$ $=0.439)$, Evaluation and Potency $\left(r_{x y}=0.372\right)$, and Activity and Potency $\left(r_{x y}=0.448\right)$ revealed the existence of a mean-low association between the different dimensions. That is, it is possible to obtain high scores on one dimension, and not so high scores in others. Next, we asked five raters to identify the assignment of each bipolar adjective to the categories of warmth and competence, according to the SCM (Fiske, Cuddy, Glick, \& $\mathrm{Xu}, 2002$ ). The raters' agreement was $100 \%$. A correspondence between the warmth and evaluation dimensions can be seen in Table 2 . In sum, the bipolar adjectives assess the basic dimensions of social judges proposed by Ossgod et al. (1957), and Fiske et al. (2002), with sufficient precision and comprehensiveness.

Table 2

Bipolar adjectives and dimensions belonging to the Osgood et al., (1957), and Fiske et al. (2002) models

\begin{tabular}{|c|c|c|}
\hline Bipolar adjectives & $\begin{array}{c}\text { Osgood et al. (1957) } \\
\text { domains }\end{array}$ & $\begin{array}{c}\text { Fiske et al. (2002) } \\
\text { domains }\end{array}$ \\
\hline Poor coworker-Good coworker & Potency & Competence \\
\hline Unable -Able & Potency & Competence \\
\hline Incompetent-Competent & Potency & Competence \\
\hline Hostile-Friendly & Evaluation & Warmth \\
\hline Intolerant-Tolerant & Evaluation & Warmth \\
\hline Crabby-Kind & Evaluation & Warmth \\
\hline Bad-Good & Evaluation & Warmth \\
\hline Negative-Positive & Evaluation & Warmth \\
\hline Child-Adult & Activity & Competence \\
\hline Passive-Active & Activity & Competence \\
\hline Dangerous-Harmless & Activity & Competence \\
\hline Resented-Placid & Evaluation & Warmth \\
\hline Resigned-Hopeful & Evaluation & Warmth \\
\hline Irresponsible-Responsible & Activity & Competence \\
\hline Idle-Worker & Potency & Competence \\
\hline Sad-Happy & Evaluation & Warmth \\
\hline
\end{tabular}

Next, additional elements were included to be rated among the 16 bipolar adjectives: The self, the ideal self, a friend, an enemy or an individual who is not trusted, an individual with intellectual disabilities, an individual with physical disabilities, and an individual with Down syndrome. The SD was then distributed for additional analyses. 


\section{Procedure and data analysis}

Data were collected from March to December 2014. We employed the usual format for this technique (Mariani \& Allen, 2014), consisting of a 7-point scale. High scores (i.e., 5, 6 or 7) reflect the emergent, desirable or positive pole of the construct (i.e., "good") versus implicit or less desirable or negative pole (e.g., "bad"), identified with low scores (1, 2 or 3$)$. Statistical analysis was performed using SPSS Statistics (version 15). Routine descriptive analysis, together with Chi-squared tests for categorical data, tests statistics (i.e., Cronbach's alpha for reliability analysis, and exploratory factor analysis for construct validity analysis), and Pearson's correlation for continuous variables were performed. Differences between continuous variables were determined by related t-tests and one-way analysis of variance (ANOVA). An alpha $=0.05$ was set for all the analyses. Additionally, intercoder reliability indexes were calculated with the online utility Recal (Freelon, 2010, 2013). Computation of the Principal Components Analysis (PCA) and the graphics display of the two-dimensional plot were calculated with the Idiogrid software (Grice, 2002).

\section{Results}

According to our first hypothesis, judgments about oneself (self and ideal self) will be characterized with positive (i.e., emergent) characteristics, while the different groups with disabilities will be characterized with less desirable characteristics. Table 3 depicts the main results concerning average scores for each element on potency, evaluation, and activity. It also shows the percentage of extreme scores on the implicit (i.e., scores from 1 to three) and the emergent (scores from 5 to 7) poles, and on neutral, ambiguity or undefined (i.e., score of 4) responses. Thus, according to our predictions, the Self and Ideal Self average scores are higher than the scores for the other groups. Ratings on Friends tend to be located between our Self and our Ideal Self, denoting proximity. The different groups with disabilities are farther from ourselves, and the percentage of responses in the emergent pole is less, above all the group with intellectual disabilities.

In addition, ANOVA test revealed that nonsignificant differences on ratings of elements concerning individuals with disabilities were found, regardless of having or not previous contact with these individuals. Similarly, no significant differences were found based on the year (freshmen, sophomore, etc.) of the students.

\section{Table 3}

Descriptive statistics on potency, activity and evaluation for the different elements of the Semantic Differential

\begin{tabular}{lrlrrr}
\hline \multicolumn{1}{c}{ Elements } & Mean & S.D. & Implicit (\%) & Ambiguity (\%) & Emergent (\%) \\
\hline Potency & & & & & \\
Self & 5.89 & 0.61 & 1.24 & 5.25 & 93.51 \\
Ideal Self & 6.77 & 0.34 & 0.00 & 0.69 & 99.31 \\
Friend & 6.09 & 0.73 & 3.18 & 3.59 & 93.23 \\
Enemy & 3.91 & 1.21 & 41.44 & 18.37 & 40.19 \\
Intellectual Disability & 5.32 & 0.96 & 6.63 & 18.92 & 74.45 \\
Physical Disability & 5.48 & 0.88 & 3.73 & 18.23 & 78.04 \\
$\quad$ Down syndrome & 5.61 & 0.93 & 4.42 & 15.88 & 79.70 \\
Evaluation & & & & & \\
Self & 5.42 & 0.71 & 6.63 & 10.84 & 82.53 \\
Ideal Self & 6.46 & 0.48 & 0.48 & 3.87 & 95.65 \\
Friend & 5.66 & 0.82 & 7.60 & 11.19 & 81.22 \\
Enemy & 3.79 & 1.24 & 40.33 & 26.52 & 33.15 \\
Intellectual Disability & 5.42 & 0.71 & 6.63 & 18.92 & 74.45 \\
Physical Disability & 6.46 & 0.48 & 3.73 & 18.23 & 78.04 \\
Down syndrome & 5.66 & 0.82 & 0.76 & 16.71 & 82.53 \\
Activity & & & & & \\
Self & 5.63 & 0.56 & 4.42 & 12.98 & 82.60 \\
Ideal Self & 6.01 & 0.67 & 3.45 & 8.98 & 87.57 \\
Friend & 5.56 & 0.92 & 9.94 & 10.64 & 79.42 \\
Enemy & 3.99 & 1.07 & 40.61 & 22.79 & 36.60 \\
Intellectual Disability & 4.74 & 0.92 & 18.51 & 27.90 & 53.59 \\
Physical Disability & 5.34 & 0.91 & 5.80 & 25.14 & 69.06 \\
Down syndrome & 4.89 & 0.97 & 19.06 & 21.69 & 59.25 \\
\hline
\end{tabular}

Continuing with our first hypothesis, we expect that judgments about ourselves will be described as both warm and competent and Table 4 shows that those average scores are in fact, high for Self-scores. According to our second prediction, average scores on Self show the primacy effect of competence over warmth. Friends, enemies, and people with physical disability show that effect as well. On the contrary, the Ideal Self, people with intellectual disabilities, and people with Down Syndrome show the reverse pattern, which could denote distance in the judgments.

As we predicted in our third hypothesis, people with different disability levels are the subject of mixed feelings, and so, while in ratings on 
individuals with physical disabilities the primacy of competence vs. warmth dimension appears, for the ratings of individuals with intellectual disabilities and with Down syndrome, the pattern is reversed.

As we stated in our fourth hypotheses, the primacy of warmth over competence appears on judgments of distant elements, whereas for oneself and close elements, the opposite pattern appears. Moreover, analysis of differences in mean scores (repeated measures t-test) indicates that self-scores on competence were significantly higher than self-scores on warmth. Conversely, warmth scores for intellectual disability and Down syndrome are significantly higher than competence scores. Therefore, the paternalistic pattern, which in turn increases the possibility of arousing emotions such as overprotection or pity, appears more clearly in these two groups. These results support the fifth hypothesis.

Table 4

Competence and warmth scores for the different elements, with Pearson's correlations, and repeated measures $t$-Tests

\begin{tabular}{|c|c|c|c|c|c|c|c|}
\hline \multirow{2}{*}{ Elements } & \multicolumn{2}{|c|}{ Competence } & \multicolumn{2}{|c|}{ Warmth } & \multirow[b]{2}{*}{$r_{\mathrm{xy}}$} & \multirow{2}{*}{$t$} & \multirow{2}{*}{$p$} \\
\hline & Mean & SD & Mean & SD & & & \\
\hline Self & 5.76 & 0.49 & 5.42 & 0.71 & $0.414 * *$ & 6.74 & $<0$ \\
\hline Ideal Self & 6.39 & 0.42 & 6.46 & 0.48 & $0.633 * *$ & -2.68 & 0.008 \\
\hline Friend & 5.82 & 0.77 & 5.66 & 0.82 & $0.523 * *$ & 2.89 & 0.004 \\
\hline Enemy & 3.95 & 1.05 & 3.79 & 1.24 & $0.522 * *$ & 1.86 & 0.064 \\
\hline Intellectual disability & 5.03 & 0.87 & 5.60 & 0.82 & $0.721^{* *}$ & -12.02 & $<0$ \\
\hline Physical disability & 5.41 & 0.83 & 5.29 & 1.00 & $0.829 * *$ & 3.04 & 0.003 \\
\hline Down syndrome & 5.25 & 0.87 & 5.86 & 0.87 & $0.729 * *$ & -12.91 & $<0$ \\
\hline
\end{tabular}

Finally, using the Idiogrid software, we calculated mean scores for each element and we performed a Principal Components Analysis (PCA) (promax rotation) to summarize the numerical information from the Grid. The analysis resulted in two components. The first component, with an eigenvalue of 13.27 , explains $82.94 \%$ of total variance. The second component, with an eigenvalue of 1.54 explains $9.61 \%$ of total variance. The cumulative explained variance was $92.55 \%$. Results are summarized in Figure 1. By looking at the first component, all the emergent poles of the constructs are on the right side of the graphic. The ideal self is located at the right side of the first component, in contrast to the Enemy element that is plotted on the opposite side. In consequence, the first component seems to deal with the evaluative (good vs. bad) or warmth (warmth vs. cold) component of social judgments. Meanwhile, the second component seems to deal with the competence dimension, given that the top part of the graphic includes constructs such as adult, competent, able, etc. Most of the elements are well-defined by this two-dimensional space, except Physical disabilities. The elements concerning people with intellectual disabilities and people with Down Syndrome are located toward the inferior pole of the component on competence, denoting low ratings on this component. Taking in mind these results, it is possible to say that the elements plotted in the first quadrant: Self, Friend, and Ideal self are rated as positive and competent. The second quadrant includes the element Enemy that is defined by negative evaluation and high competence. The third quadrant, which includes people with intellectual disabilities, is mostly defined by low competence. The fourth quadrant includes the label Down syndrome which is characterized by positive evaluation and low competence. It is also defined by constructs related to warmth dimension.

Figure 1

Principal Components Analysis (PCA) promax rotation

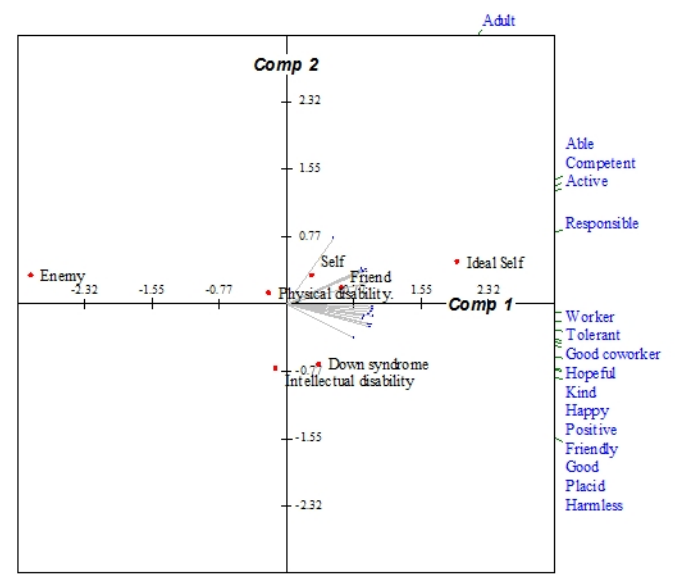




\section{Discussion}

The combined utilization of two models on social perception, together with the Idiogrid software have allowed us to graphically present social representation and assigned status of different groups of people. Several findings are noteworthy as well. First, individuals without disabilities tend to rate people with disabilities as more similar to those who share the label, than to those who do not. Also, regarding the debate on competence vs. warmth, people with a cognitive condition (i.e., intellectual disability or Down syndrome) are considered more warm than competent, whereas those who do not share such condition are considered more competent than warm. The label associated with a cognitive condition appears to have a halo effect resulting in a paternalistic and stereotyped view that reduces the perception of interpersonal differences between diverse groups. Considering that stereotypes develop to justify prejudice (Crandall, Bahns, Warner, \& Schaller, 2011; Salas et al., 2017), and that different disability labels evoke negative expectancies and bias (Foster \& Ysseldyke, 1976), it is important to utilize "sound" and "simple" graphic representations of our social world to further promote our understanding of the role played by our bias, prejudices, and expectancies, as a starting point to develop strategies to remove those stereotypes.

A more detailed analysis according to the proposed model by Osgood et al. (1957) allows recognition that, while individuals with physical disabilities are subject to relatively better ratings, individuals with intellectual disabilities receive the lowest scores, and individuals with Down syndrome obtain medium-high ratings. Added to this is the fact that, while the group of people with physical disabilities achieve a high percentage of responses that denote uncertainty or ambiguity, the Down syndrome element obtains the highest percentage of responses in the emerging pole for potency, activity and evaluation. Finally, people with intellectual disabilities obtain the highest percentage of responses in the implicit pole for the activity domain. These findings suggest that people with Down syndrome are subject to relatively more favorable attitudes than other disability conditions. In this group, the responses denoting ambiguity are relatively low, indicating a greater willingness to characterize this group as very similar to each other. In other words, contrary to one of the classic premises of the semantic differential, where a score of four is considered neutral or "meaningless" (Clevenger, Lazier, \& Clark, 1968), we consider this score as indicative of efforts to reduce overgeneralization and simplification, by stating that "it depends" on the specific characteristics of the individual under consideration. However, the attribution of features to the Down syndrome group, such as sympathy or kindness, are labels under which paternalistic attitudes are hidden and can ultimately reduce their rights. If we also consider that, in the group of people with physical disabilities, there is a primacy of competence vs. warmth compared to what happens to people with intellectual disabilities and Down syndrome, in which the dimension warmth prevails over competence, it seems clear that goodness over capability is a reasonably widespread perception. Additionally, although the Ideal Self stresses warmth over competence as well, the differences appear even more evidently after the PCA. Thus, while the Ideal Self obtains high ratings in evaluation and competence, people with intellectual disabilities and Down syndrome are rated as having low competence.

An additional noteworthy result relates to the fact that, although the three-dimensional model proposed by Osgood et al. (1957) can be effectively and reliably used to identify social perceptions and stereotypes as well as concomitant profiles and even emotions. The bidimensional model resulting from the Stereotype Content Model proposed by Fiske et al. (2002) fits the perception of differences better when rating the interpersonal world of those well-known and even unknown protagonists. This finding agrees with Sayans-Jiménez et al., (2017) where bi-factor models showed greater utility to directly and more easily explore the stereotype content including its evaluative content. Thus, Principal Components Analysis 
yielded two factors with high explanatory power, the first one dealing with the evaluative domain regarding warm vs. cold characteristics where the second one dealing with the competence dimension. As this dimension decreases, the elements are considered less capable and competent but, at the same time, holders of personal characteristics more related to goodness and lacking danger and menace. These results agree with previous findings with different assessment techniques (Carlsson \& Björklund, 2010; Cuddy et al., 2008; Cuddy et al., 2009; de Paula Couto \& Koller, 2012; Durante, Capozza, \& Fiske, 2010; Nier et al., 2013), and serve to reclaim a more egalitarian vision focused on rights, equal opportunities and nondiscrimination against people with disabilities. Otherwise, we will be helping to maintain stereotypes that in turn perpetuate inequality.

Finally, some cautions should be noted relating to the sampling selection and size and the fact that participants in the second study were all college students. Further studies should focus on other possible variables that could be influencing current results. Likewise, the utilization of additional measures will help analyze additional psychometric properties (e.g., convergent validity) of the developed measure. Also, the inclusion of additional elements may help us analyze social perception, stereotypes, and prejudices toward many other disadvantaged groups who see how their status quo is justified for the sake of their own health or personal safety or that of those around them.

\section{References}

Abele, A. E., Cuddy, A. J. C., Judd, C. M., \& Yzerbyt, V. Y. (2008). Fundamental dimensions of social judgment. European Journal of Social Psychology, 38(7), 10631065. https://doi.org/10.1002/ejsp.574

Ahlborn, L. J., Panek, P. E., \& Jungers, M. K. (2008). College students' perceptions of persons with intellectual disability at three different ages. Research in Developmental
Disabilities, 29(1), 61-69. https://doi.org/10. 1016/j.ridd.2006.11.001

Álvarez Pascual, P., \& Jenaro, C. (2018). Evaluación de la Identidad del Recluso mediante la Técnica de la Rejilla. Revista Iberoamericana de Diagnóstico y Evaluación e Avaliação Psicológica. RIDEP, 47(2), 5-20. https://doi.org/10.21865/RIDEP47.2.01

Araten-Bergman, T., \& Werner, S. (2017). Social workers' attributions towards individuals with dual diagnosis of intellectual disability and mental illness. Journal of Intellectual Disability Research, 61 (2), 155-167. https:// doi.org/10.1111/jir.12300

Arias, V., Arias, B., Verdugo, M. Á., Rubia, M., \& Jenaro, C. (2016). Evaluación de actitudes de los profesionales hacia las personas con discapacidad. Siglo Cero, 47(2), 7-41. https ://doi.org/10.14201/scero2016472741

Bąk, O. (2001). The proposal of a modification of the semantic differential in research on the stereotype of the mentally ill. Archives of Psychiatry and Psychotherapy, 3(2), 75-88.

Binggeli, S., Krings, F., \& Sczesny, S. (2014). Stereotype content associated with immigrant groups in Switzerland. Swiss Journal of Psychology, 73(3), 123-133. https ://doi.org/10.1024/1421-0185/a000133

Carlsson, R., \& Björklund, F. (2010). Implicit stereotype content: Mixed stereotypes can be measured with the implicit association test. Social Psychology, 41 (4), 213-222. http s://doi.org/10.1027/1864-9335/a000029

Chin, W. W., Johnson, N. and Schwarts, A. (2008), A fast form approach to measuring technology acceptance and other constructs. MIS Quarterly, 32(4), 687-704. Retrieved from https://misq.org/a-fast-form-approach -to-measuring-technology-acceptance-and -other-constructs.html

Clevenger, T., Jr., Lazier, G. A., \& Clark, M. L. (1968). The influence of certain factors on response to the semantic differential. Public Opinion Quarterly, 32 (4), 675-679.

Collange, J., Fiske, S. T., \& Sanitioso, R. (2009). Maintaining a positive self-image by stereotyping others: Self-threat and 
the Stereotype Content Model. Social Cognition, 27(1), 138-149. https://doi.org/1 $0.1521 /$ soco.2009.27.1.138

Cottrell, C. A., \& Neuberg, S. L. (2005). Different emotional reactions to different groups: A sociofunctional threat-based approach to "prejudice." Journal of Personality and Social Psychology, 88(5), 770-789. https://doi.org/10.1037/0022-351 4.88.5.770

Crandall, C. S., Bahns, A. J., Warner, R., \& Schaller, M. (2011). Stereotypes as justifications of prejudice. Personality and Social Psychology Bulletin, 37(11), 1488-1498. https://doi.org/10.1177/014616 7211411723

Cuddy, A. J. C., Fiske, S. T., \& Glick, P. (2008). Warmth and competence as universal dimensions of social perception: The stereotype content model and the BIAS map. In M. P. Zanna (Ed.), Advances in experimental social psychology (Vol. 40, pp. 61-149). San Diego, CA: Elsevier Academic Press.

Cuddy, A. J. C., Fiske, S. T., Kwan, V. S. Y., Glick, P., Demoulin, S., Leyens, J. P., ... Ziegler, R. (2009). Stereotype content model across cultures: Towards universal similarities and some differences. British Journal of Social Psychology, 48, 1-33. https://doi.org/10.134 8/014466608X314935

de Paula Couto, M. C. P., \& Koller, S. H. (2012). Warmth and competence: Stereotypes of the elderly among young adults and older persons in Brazil. International Perspectives in Psychology: Research, Practice, Consultation, 1(1), 52-62. https://doi.org/10.1037/a0027 118.

Dijker, A., van Alphen, L., Bos, A., van den Borne, B. \& Curfs, L. (2011) Social integration of people with intellectual disability: Insights from a social psychological research programme. Journal of Intellectual Disability Research, 55, 885-894. https://doi.org/10.1111/j.1365-27 88.2011.01446.x

Durante, F., Capozza, D., \& Fiske, S. T. (2010). The stereotype content model: The role played by competence in inferring group status. TPM-Testing, Psychometrics, Methodology in Applied Psychology, 17(4), 187-199. Retrieved from http://psycnet.apa .org/record/2011-00522-001

Durante, F., Tablante, C. B., \& Fiske, S. T. (2017). Poor but warm, rich but cold (and competent): Social classes in the stereotype content model. Journal of Social Issues, 73(1), 138-157. https://doi.org/10.1111/jos i. 12208

Durante, F., Volpato, C., \& Fiske, S. (2010). Using the stereotype content model to examine group depictions in fascism: An archival approach. European Journal of Social Psychology, 40(3), 465-483. https://d oi.org/10.1002/ejsp.637

Fellinghauer, B. A. G., Roth, A., Bugari, K., \& Reinhardt, J. D. (2011). Construct validity, test-retest reliability, and internal consistency of the Photo Elicitation Semantic Differential Scale (PESD) in disability studies. Journal of Developmental and Physical Disabilities, 23(3), 257-265. htt ps://doi.org/10.1007/s10882-010-9224-y

Fiske, S. T., Cuddy, A. J. C., \& Glick, P. (2007). Universal dimensions of social cognition: Warmth and competence. Trends in Cognitive Sciences, 11(2), 77-83. https://d oi.org/10.1016/j.tics.2006.11.005

Fiske, S. T., Cuddy, A. J. C., Glick, P., \& Xu, J. (2002). A model of (often mixed) stereotype content: Competence and warmth respectively follow from perceived status and competition. Journal of Personality and Social Psychology, 82(6), 878-902. https://doi.org/10.1037//0022-35 14.82.6.878

Follmer, K. B., \& Jones, K. S. (2017). Stereotype content and social distancing from employees with mental illness: The moderating roles of gender and social dominance orientation. Journal of Applied Social Psychology, 47(9), 492-504. https://d oi.org/10.1111/jasp.12455

Foster, G., \& Ysseldyke, J. (1976). Expectancy and halo effects as a result of artificially induced teacher bias. Contemporary 
Educational Psychology, 1(1), 37-45. https:// doi.org/10.1016/0361-476X(76)90005-9

Freelon, D. (2010). ReCal: Intercoder reliability calculation as a web service. International Journal of Internet Science, 5(1), 20-33. Retrieved from http://www.ijis.net/ijis5_1/i jis5_1_freelon.pdf

Freelon, D. (2013). ReCal OIR: Ordinal, interval, and ratio intercoder reliability as a web service. International Journal of Internet Science, 8, 10-16. Retrieved from http://ww w.ijis.net/ijis8_1/ijis8_1_freelon.pdf

Fresson, M., Dardenne, B., Geurten, M., \& Meulemans, T. (2017). Stereotype content of people with acquired brain injury: Warm but incompetent. Journal of Applied Social Psychology, 47(10), 539-552. https://doi.org /10.1111/jasp.12459

Goreczny, A. J., Bender, E. E., Caruso, G., \& Feinstein, C. S. (2011). Attitudes toward individuals with disabilities: Results of a recent survey and implications of those results. Research in Developmental Disabilities, 32 (5), 1596-1609. https://doi.or g/10.1016/j.ridd.2011.02.005

Grice, J. W. (2002). Idiogrid: Software for the management and analysis of repertory grids. Behavior Research Methods, Instruments, $\mathcal{E}$ Computers, 34, 338-341. https://doi.org/10. 3758/BF03195461

Jahoda, A. \& Markova, I. (2004) Coping with social stigma: People with intellectual disabilities moving from institutions and family home. Journal of Intellectual Disability Research, 48, 719-729. https://doi.org/10.11 11/j.1365-2788.2003.00561.x

Kervyn, N., Fiske, S. T., \& Yzerbyt, V. Y. (2013). Integrating the stereotype content model (warmth and competence) and the Osgood semantic differential (evaluation, potency, and activity). European Journal of Social Psychology, 43(7), 673-681. https://doi.org/ 10.1002/ejsp.1978

Kotzur, P. F., Forsbach, N., \& Wagner, U. (2017). Choose your words wisely: Stereotypes, emotions, and action tendencies toward fled people as a function of the group label.
Social Psychology, 48(4), 226-241. https://d oi.org/10.1027/1864-9335/a000312

Krippendorff, K. (2004). Content analysis: An introduction to its methodology. Thousand Oaks, CA: Sage.

Landis, J. R., \& Koch, G. G. (1977). The measurement of observer agreement for categorical data. Biometrics, 33, 159-174.

Lifshitz, H. (2002). Attitudes toward aging in adult and elderly people with intellectual disability. Educational Gerontology, 28(9), 745-759. https://doi.org/10.1080/03601270 290099912

Lindqvist, A., Björklund, F., \& Bäckström, M. (2017). The perception of the poor: Capturing stereotype content with different measures. Nordic Psychology, 69(4), 231-247. https://doi.org/10.1080/19 012276.2016 .1270774

Mariani, B., \& Allen, L. R. (2014). Development and psychometric testing of the Mariani Nursing Career Satisfaction Scale. Journal of Nursing Measurement, 22 (1), 135-144. ht tps://doi.org/10.1891/1061-3749.22.1.135

Miyahara, M., \& Register, C. (2000). Perceptions of three terms to describe physical awkwardness in children. Research in Developmental Disabilities, 21(5), 367-376. https://doi.org/10.1016/S0891-42 $22(00) 00049-4$

Nelissen, P. T. J. H., Hülsheger, U. R., van Ruitenbeek, G. M. C., \& Zijlstra, F. R. H. (2016). How and when stereotypes relate to inclusive behavior toward people with disabilities. The International Journal of Human Resource Management, 27(14), 1610-1625. https://doi.org/10.1080/095851 92.2015.1072105

Nier, J. A., Bajaj, P., McLean, M. C., \& Schwartz, E. (2013). Group status, perceptions of agency, and the correspondence bias: Attributional processes in the formation of stereotypes about high and low status groups. Group Processes $\mathcal{E}$ Intergroup Relations, 16(4), 476-487. https://doi.org/10 $.1177 / 1368430212454925$

Oexle, N., Müller, M., Kawohl, W., Xu, Z., Viering, S., Wyss, C., .. . Rüsch, N. 
(2017). Self-stigma as a barrier to recovery: A longitudinal study. European Archives of Psychiatry and Clinical Neuroscience. https:// doi.org/10.1007/s00406-017-0773-2

Oexle, N., Rüsch, N., Viering, S., Wyss, C., Seifritz, E., Xu, Z., \& Kawohl, W. (2017). Self-stigma and suicidality: A longitudinal study. European Archives of Psychiatry and Clinical Neuroscience, 267(4), 359-361. htt ps://doi.org/10.1007/s00406-016-0698-1

Oldmeadow, J. A., \& Fiske, S. T. (2012). Contentment to resentment: Variation in stereotype content across status systems. Analyses of Social Issues and Public Policy (ASAP), 12(1), 324-339. https://doi.org/10 $.1111 / \mathrm{j} .1530-2415.2011 .01277 . \mathrm{x}$

Osgood, C. E. (1952). The nature and measurement of meaning. Psychological Bulletin, 49(3), 197-237. https://doi.org/10. 1037/h0055737

Osgood, C., Suci, G., \& Tannenbaum, P. (1957). The measurement of meaning. Urbana, Illinois: University of Illinois Press.

Panek, P. E., \& Jungers, M. K. (2008). Effects of age, gender, and causality on perceptions of persons with mental retardation. Research in Developmental Disabilities, 29(2), 125-132. h ttps://doi.org/10.1016/j.ridd.2007.01.002

Panek, P. E., \& Smith, J. L. (2005). Assessment of terms to describe mental retardation. Research in Developmental Disabilities, 26(6), 565-576. https://doi.org/10.1016/j.ridd.200 4.11 .009

Polo Sánchez, M. T., Fernández Jiménez, C., \& Díaz Batanero, C. (2011). Estudio de las actitudes de estudiantes de ciencias sociales y psicología: Relevancia de la información y contacto con personas discapacitadas. Universitas Psychologica, 10(1), 113-123. Retrieved from http://revistas.javeriana.ed u.co/index.php/revPsycho/issue/view/41

Ponsi, G., Panasiti, M. S., Scandola, M., \& Aglioti, S. M. (2016). Influence of warmth and competence on the promotion of safe in-group selection: Stereotype content model and social categorization of faces. The Quarterly Journal of Experimental
Psychology, 69(8), 1464-1479. https://doi.or g/10.1080/17470218.2015.1084339

Richetin, J., Durante, F., Mari, S., Perugini, M., \& Volpato, C. (2012). Primacy of warmth versus competence: A motivated bias? The Journal of Social Psychology, 152(4), 417-435. https://doi.org/10.1080/00224545 .2011 .623735

Salas, N., Castillo, D., Martín, C. S., Kong, F., Thayer, L. E., \& Huepe, D. (2017). Immigration in school: Characterization of prejudice towards migrants schoolchildren in Chile. Universitas Psychologica, 16(5), 1-15. https://doi.org/10.11144/Javeriana.up sy16-5.iecp

Sayans-Jiménez, P., Cuadrado, I., Rojas, A. J., \& Barrada, J. R. (2017). Extracting the evaluations of stereotypes: Bi-factor model of the stereotype content structure. Frontiers in Psychology, 8, 1-12. https:// doi.org/10.3389/fpsyg.2017.01692

Smith, E. R., \& Semin, G. R. (2007). Situated social cognition. Current Directions in Psychological Science, 16, 132-135. https://d oi.org/10.1111/j.1467-8721.2007.00490.x

Stephan, W. G., \& Stephan, C. W. (2000). An integrated threat theory of prejudice. In S. Oskamp (Ed.), Reducing prejudice and discrimination (pp. 23-46). Hillsdale, NJ: Erlbaum.

Verdugo, M. A., Arias, B., \& Jenaro, C. (1994). Actitudes hacia las personas con minusvalía. Madrid: Ministerio de Asuntos Sociales, INSERSO.

Wojciszke, B., \& Abele, A. E. (2008). The primacy of communion over agency and its reversals in evaluations. European Journal of Social Psychology, 38(7), 1139-1147. https:/ /doi.org/10.1002/ejsp.549

\section{Notes}

* $\quad$ Research article. 